\title{
Technical efficiency of public health centers in three districts in Ethiopia: two-stage data envelopment analysis
}

\author{
Firew Tekle Bobo ${ }^{1 *}$, Mirkuzie Woldie ${ }^{2,3}$, Muluemebet Abera Wordofa ${ }^{4}, G^{2}$ ebeyehu Tsega ${ }^{2}$, \\ Tesfamichael Alaro Agago ${ }^{2}$, Kifle Wolde-Michael ${ }^{5}$, Nuraddis Ibrahim ${ }^{6}$ and Elias Ali Yesuf ${ }^{2,7}$
}

\begin{abstract}
Objective: The aim of the study was to measure technical and scale efficiency of public health centers in three districts of Jimma zone, Ethiopia. A two-stage data envelopment analysis was used. First, we estimated technical and scale efficiency of the health centers. In the second stage, institutional and environmental factors were against technical efficiency of the health centers to identify factors associated to efficiency of the health centers.

Results: Eight out of the 16 health centers in the study were found to be technically efficient, with an average score of $90 \%$ (standard deviation $=17 \%$ ). This indicates that on average they could have reduce their utilization of all inputs by about 10\% without reducing output. On the other hand, 8 out of 16 health centers were found to be scale efficient, with an average scale efficiency score of $94 \%$ (standard deviation $=9 \%$ ). The inefficient health centers had an average scale score of $89 \%$; implying there is potential for increasing total outputs by about $11 \%$ using the existing capacity/size. Catchment population and number of clinical staff were found to be directly associated with efficiency, while the number of nonclinical staff was found to be inversely associated with efficiency.
\end{abstract}

Keywords: Technical efficiency, Scale efficiency, Health centers, Inputs, Output, Data envelopment analysis

\section{Introduction}

A number of countries in Africa have been inefficient in the use of available resources. From the total fund allocated to the health system worldwide, $20-40 \%$ of all health resources being wasted. The achievement of national and international health development targets requires not only an increase in funding, but also efficient use of available resources and greater equity in financing and accessing quality health care [1-4]. In Ethiopia, the government is majorly concerned with addressing access and coverage issues and there is lack of empirical evidence on the level of efficiency of health centers in the overall delivery of health services [4-6].

Health centers play a central role in Primary Health Care Unit, which are a vital part of Ethiopia's public

\footnotetext{
*Correspondence: free11messi@gmail.com

${ }^{1}$ Department of Public Health, Wollega University, Nekemte, Ethiopia

Full list of author information is available at the end of the article
}

health system. Significant investments are directed at improving the quality and equitable delivery of health services provided at health center level, with a strategic emphasis on crucial and interrelated elements-accessibility, affordability, and sustainability [7].

However, not much has been done to assess the efficiency of those health facilities. Health center is deemed efficient, if it can produce the maximum possible output using a given amount of input. Data envelopment analysis (DEA) is an important tool that is used to measure efficiency of decision-making units (Health centers in this case). DEA is a methodology directed to frontiers rather than central tendencies.

Therefore, using data envelopment analysis (DEA) framework, this study aimed to determine technical efficiency, scale efficiency of individual health centers in three districts of Ethiopia. Moreover, we also estimated the amount of input reduction and/or output increases needed to make inefficient health centers efficient. 
Finally, we aimed to identify factors associated with efficiency of health centers.

\section{Main text}

Methods

\section{Study design and setting}

Institution based cross sectional study design was employed. All health centers in three districts; namely, Mana, Kersa and Seka chekorsa of Jimma zone were included in the study.

\section{DEA conceptual framework}

To assess differences in the productive efficiency of health centers, we used DEA, a mathematical programming based method that converts multiple input and output measures into a single summary measure of productive efficiency. DEA is based on relative efficiency concepts proposed by Farrell but Charnes et al. extended and developed Farrell's approach $[8,9]$.

Overall this model, measures the ability of the health center to produce a given level of output using the minimum amount of input or alternatively the maximum amount of output using a given amount of input. The formula is given by $[8,9]$.

$$
\operatorname{Max}_{h_{o}}=\frac{\sum_{r=1}^{s} u_{r} y_{i j o}}{\sum_{i=1}^{m} v_{i} x_{i j o}}
$$

Subject to:

$$
\begin{aligned}
& \frac{\sum_{r=1}^{s} u_{r} y_{i} j_{o}}{\sum_{i=1}^{m} v_{i} y_{i} j_{o}} \leq 1, \quad j=1, \ldots j_{o}, \ldots n \\
& u_{r} \geq 0 r=1, \ldots, s \text { and } v_{i} \geq 0, \quad i=1, \ldots m
\end{aligned}
$$

$y_{\mathrm{r} j}:$ amount of output $r$ from health center $\mathrm{j}, \mathrm{x}_{\mathrm{ij} \text { : }}$ amount of input $i$ to health center $j$, $u_{r}$ : weight given to output $r$, $v_{i}$ : weight given to input $i, n$ : number of health centers, $s$ : number of outputs, m: number of inputs.

Constant returns to scale (CRS) model Measured using Charnes, Cooper and Rhodes (CCR) DEA model. Measures health centers ability to produce expected/required amount of output from a given amount of input. The formula is given by;

$$
\operatorname{Max} h_{o}=\sum_{r=1}^{s} u_{r} y_{r j o}
$$

Subject to:

$$
\operatorname{Max}_{o}=\sum_{r=1}^{s} u_{r} y_{r j o}=1
$$

$$
\begin{aligned}
& \operatorname{Max}_{h_{o}}=\sum_{r=1}^{s} u_{r} y_{r}-\sum_{r=1}^{s} v_{i} x_{i j} \leq 0 \quad j=1, \ldots, n \\
& u_{r}, v_{i} \geq 0
\end{aligned}
$$

Variable returns to scale (VRS) model Measured using Banker, Charnes and Cooper (BCC) DEA model. This model is effective to assess efficiency of the health centers when all inputs proportionally increase and we face different level of output production.

$$
\operatorname{Max} h_{o}=\sum_{r=1}^{s} u_{r} y_{r j o}+z_{j o}
$$

Subject to:

$$
\begin{aligned}
& \operatorname{Max} h_{o}=\sum_{r=1}^{s} v_{i r} x_{i j o}+z_{j o}=1 \\
& \operatorname{Maxh}_{o}=\sum_{r=1}^{s} u_{r} y_{r}-\sum_{r=1}^{s} v_{i} x_{i j}+z_{j o} \leq 0 \quad j=1, \ldots, n \\
& u_{r}, v_{i} \geq 0
\end{aligned}
$$

\section{Data collection procedure}

The instrument was prepared after reviewing different literatures. The Ethiopian standard for health centers requirement [10] and other literatures [11-14] were used to prepare the document review check list in order to collect the data from the health centers. The contents of the document review checklist (data collection instrument) includes, input and output data and environmental factor such as catchment population of those health centers in the year of 2013/2014.

\section{Data analysis}

First, descriptive statistics of all input and output variables were calculated by using Stata 13 . The mean, standard deviation (SD), minimum and maximum values of all input and output variables were presented. Subsequently, the technical efficiency, scale efficiency scores and input reduction and/or output increases were computed using the DEA Programme, version 2.1 (DEAP 2.1) developed by Coelli [8]. Health facilities that assume the "best practice frontier" are assigned an efficiency score of one (or $100 \%$ ) and are said to be technically efficient compared to their peers. The efficiency of the health facilities below 
the efficiency frontier is measured in terms of their distance from the frontier. The inefficient health facilities are assigned a score between one and zero. The larger the score the more efficient a health facility is [8].

In the second stage, the estimated technical efficiency scores obtained from the DEA was considered the dependent variable and regressed against the set of institutional and environmental variables using a Tobit model.

\section{Results}

\section{Descriptive statistics of input and output data}

The health centers used 25 Health officers, 106 clinical Nurses, 30 Midwives, 29 laboratory technicians, and 19 Druggists all together to provide care for 163,698 outpatients, 11,077 pentavalent three times for children, four and more antenatal care (ANC) for 12,279 pregnant women, delivery care for 9504 mothers, family planning for 33,249 women all together. Table 1 shows the difference between efficient (eight health centers) and inefficient eight health centers by the inputs used and outputs they produced.

\section{Efficiency analysis}

The overall average score for technical efficiency was $77 \%$ with SD of $16 \%$, CRTS technical efficiency $90 \%$ $(\mathrm{SD}=17 \%)$, for VRTS technical efficiency the average score was $94 \%(\mathrm{SD}=11 \%)$, and for scale efficiency $(\mathrm{SE})$ the average score was $94 \%(\mathrm{SD}=9 \%)$. Table 2 presents scores for constant returns to scale, variable returns to scale, scale efficiency, and returns to scale of 16 health centers.

\section{Constant return to scale (CRTS)}

From the total of 16 health centers involved in the analysis eight (50\%) had a constant return to scale technical efficiency of $100 \%$, and the rest 8 health centers were constant return to scale inefficient. Out of the 8 CRTS
Table 2 Presents, constant return to scale, variable return to scale, scale efficiency and return to scale values of each health center

\begin{tabular}{lllll}
\hline DMU & CRTS & VRTS & SE & RTS \\
\hline HC01 & 0.89 & 0.92 & 0.98 & Decreasing \\
HC02 & 1 & 1 & 1 & Constant \\
HC03 & 0.97 & 1 & 0.97 & Decreasing \\
HC04 & 0.94 & 0.96 & 0.98 & Increasing \\
HC05 & 0.5 & 0.75 & 0.67 & Increasing \\
HC06 & 1 & 1 & 1 & Constant \\
HC07 & 1 & 1 & 1 & Constant \\
HC08 & 0.91 & 1 & 0.91 & Increasing \\
HC09 & 0.68 & 0.87 & 0.78 & Increasing \\
HC10 & 1 & 1 & 1 & Constant \\
HC11 & 1 & 1 & 1 & Constant \\
HC12 & 1 & 1 & 1 & Constant \\
HC13 & 1 & 1 & 1 & Constant \\
HC14 & 1 & 1 & 1 & Constant \\
HC15 & 0.96 & 0.96 & 0.99 & Decreasing \\
HC16 & 0.54 & 0.63 & 0.85 & Increasing \\
Mean & 0.90 & 0.94 & 0.94 & \\
STD deviation & 0.17 & 0.11 & 0.09 & \\
\hline
\end{tabular}

inefficient health centers 4 (25\%) had a score between 91 and $99.99 \%$, two had a score between 50 and $59 \%$, one a score of $68 \%$, and another 1 health center had a score of $87 \%$ constant return to scale technical efficiency.

\section{Variable return to scale (VRTS)}

The findings of VRTS model shows that $10(62.5 \%)$ of the health centers had a score of $100 \%$, and the rest $6(37.5 \%)$ were found to be inefficient. Among the inefficient 3 (18.75\%) had a score between 91 and $99.99 \%$ and other three different health centers had a score between 60 and $90 \%$, two scored 87 and $75 \%$, and one scored $63 \%$.

Table 1 Inputs used and outputs produced among efficient and inefficient health centers

\begin{tabular}{|c|c|c|c|c|c|c|}
\hline \multirow[t]{2}{*}{ Inputs } & \multicolumn{3}{|c|}{ Efficient health centers } & \multicolumn{3}{|c|}{ Inefficient health centers } \\
\hline & Mean & SD & Sum & Mean & SD & Sum \\
\hline Nonclinical staff & 8.9 & 5 & 71 & 8.6 & 2.4 & 69 \\
\hline Clinical staff & 13.3 & 3.8 & 106 & 13.1 & 2 & 105 \\
\hline \multicolumn{7}{|l|}{ Outputs } \\
\hline Outpatient visits & $13,848.5$ & 6940 & 110,788 & 6614 & 3862.6 & 52,910 \\
\hline Pentavalent 3 times & 767.6 & 321.6 & 6141 & 617 & 313 & 4936 \\
\hline ANC four and more & 975.6 & 271.9 & 7805 & 559 & 226.1 & 4474 \\
\hline Delivery & 716.2 & 362.1 & 5730 & 471.7 & 150 & 3774 \\
\hline Family planning & 2429.5 & 1325.3 & 19,436 & 1726.6 & 1341 & 13,813 \\
\hline
\end{tabular}


Table 3 Presents Tobit regression model result

\begin{tabular}{|c|c|c|c|c|}
\hline \multicolumn{5}{|l|}{ Tobit regression } \\
\hline \multicolumn{5}{|l|}{ Number of obs $=16$} \\
\hline \multicolumn{5}{|l|}{$\operatorname{LR} x^{2}(5)=24.95$} \\
\hline \multicolumn{5}{|l|}{ Prob $>x^{2}=0.0001$} \\
\hline \multicolumn{5}{|l|}{ Log likelihood = 12.59} \\
\hline Efficiency & Coef. & $\mathbf{P}$ & (95\% conf. it & \\
\hline Catchment population & $7.80 \mathrm{E}-06$ & 0.013 & $2.03 \mathrm{E}-06$ & $1.36 \mathrm{E}-05$ \\
\hline Outpatient visit & $7.04 \mathrm{E}-06$ & 0.120 & $-2.17 \mathrm{E}-06$ & $1.62 \mathrm{E}-05$ \\
\hline Clinical staff & 0.06063 & 0.000 & 0.036432 & 0.084827 \\
\hline Nonclinical staff & -0.02501 & 0.039 & -0.04847 & -0.00156 \\
\hline Age & $3.64 \mathrm{E}-05$ & 0.998 & -0.02584 & 0.025911 \\
\hline _cons & -0.10668 & 0.762 & -0.86388 & 0.650522 \\
\hline /sigma & 0.079686 & & 0.044311 & 0.115062 \\
\hline \multicolumn{5}{|l|}{ Obs.summary } \\
\hline 0 & \multicolumn{4}{|c|}{ Left-censored observations } \\
\hline 8 & \multicolumn{4}{|c|}{ Uncensored observations } \\
\hline 8 & \multicolumn{2}{|c|}{ Right-censored observations } & \multicolumn{2}{|c|}{ at efficiency $=1$} \\
\hline
\end{tabular}

\section{Scale efficiency}

Table 2 shows 8 (50\%) of health centers in the three Woredas of Jimma Zone are scale inefficient. Implying that they are either too small or too large. Increasing returns to scale was the predominant form of scale inefficiency.

\section{Tobit regression analysis}

Table 3 shows the Tobit regression model results, that identifies the factors that affect efficiency of public health centers.

\section{Discussion}

The findings of the study revel that eight (50\%) of health centers were technically inefficient. Though, technical inefficiency is widely prevalent according to studies conducted in some of sub-Saharan African countries, the finding of this study is a little bit higher than others. The majority of studies in those countries present above $50 \%$ of technical inefficiency, for instance $65 \%$ of public health centers in Ghana [13], 59\% of peripheral health units in Pujehun district of Sierra Leone [12], 56\% of Public Health Centers in Kenya [15], 78\% of Public Health Centers in Ghana [16] were all found to be technically inefficient.

The average technical efficiency of the eight inefficient health centers was $90 \%$ with a standard deviation of $17 \%$. This indicates that on average they could have reduce their utilization of all inputs by about $10 \%$ without reducing output.

Differences of technical and scale efficiency results of this study with other findings in sub-Saharan Africa countries discussed above could be attributed to different reasons. This might be due to the differences of health care system and their performances. Moreover, health insurance scheme in Ghana, Kenya and Sierra Leone enable people to use health services-promotion, prevention, treatment and rehabilitation-without incurring financial hardship, which induces demand for health care and increases output produced by the health facilities.

Increasing the amount of outputs requires an increase in the demand for health care. Since, input needs of health center are standardized, reduction of inputs is not an option. In order for 8 inefficient facilities to become efficient as a group, they would have needed to increase their outpatient department visits by 23,177 (77\%), family planning by 4390 (14.5\%), immunization by 1010 (3.3\%), ANC $4^{+}$by $970(3.2 \%)$ and delivery care by $694(2.3 \%)$.

The second DEA stage analysis identified two significant factors which have positive association with efficiency. This factors were the size of catchment population and clinical staff of the health centers. On the other hand, nonclinical staff was found to affect efficiency negatively.

In conclusion, only half of the health centers were found to be scale efficient. There was barely a difference between the eight efficient health centers and the other eight inefficient health centers, in the amount of health care workers they used. However, clients/patients who were served at the efficient health centers were more than twice in number than those clients who were served at inefficient health centers. Considering the scarce resource available to the health sector, the findings indicate that performance improvement measures have to be taken. 


\section{Limitations of the study}

- The analysis reported in this article is based on health centers inputs and outputs data for 2013/2014. Much has changed since 2013/2014, particularly in terms of the country's socioeconomic and health development. The results are not meant to uncritically inform current decision-making processes, but rather to illustrate the potential value of such efficiency analyses.

- Limitations of the study may include, DEA attributes any deviation from the "best practice frontier" to inefficiency, while some could be due to statistical noise, e.g. epidemics or measurement errors.

- Expenditures on pharmaceuticals and non-pharmaceutical supplies and other nonwage expenditures among the inputs were not included in the study due to the lack of data.

\section{Abbreviations}

CRS: constant return to scale; VRS: variable return to scale; SE: scale efficiency; DEA: data envelopment analysis; DMU: decision making units: WHO: World Health Organization; PHC: Primary Health Care; PHCU: Primary Health Care Units; MOH: Ministry Of Health (Federal Democratic Republic of Ethiopia).

\section{Authors' contributions}

FT, EAY, MAW, GT, TAA, KW, MW and NI conceived and designed the study, FT, EAY, and MW analyzed the data and drafted the report; FT, EAY, MAW, GT and MW contributed in the write-up and revision of the manuscript. All authors read and approved the final manuscript.

\section{Author details}

1 Department of Public Health, Wollega University, Nekemte, Ethiopia.

${ }^{2}$ Department of Health Policy and Management, Jimma University, Jimma, Ethiopia. ${ }^{3}$ Fenot Project of Harvard T.H. Chan School of Public Health, Boston, USA. ${ }^{4}$ Department of Population and Family Health, Jimma University, Jimma, Ethiopia. ${ }^{5}$ Department of Epidemiology, Jimma University, Jimma, Ethiopia.

${ }^{6}$ Department of Biomedical Science, Jimma University, Jimma, Ethiopia.

${ }^{7}$ CIHLMU Center for International Health, Ludwig-Maximilians-Universität

München, Munich, Germany.

\section{Acknowledgements}

We would like to acknowledge the support and inputs One Health, Jimma University and Wollega University. We would like to thank One Health Central and East Africa for funding the study. The authors would also like to thank head of health centers, in Mana, Kersa and Seka chekorsa Woreda health office for their support during the study period.

\section{Competing interests}

The authors declare that they have no competing interests.

\section{Availability of data and materials}

All data generated or analyzed during this study are included in this published article.

\section{Consent for publication}

Not applicable.

\section{Ethics approval and consent to participate}

The study does not include human subjects and it is based on secondary data. Ethical clearance was obtained from Research and Ethics committee of the Jimma University College of Health sciences. Consent to participate in the study was received from the head of health centers.

\section{Funding}

This study was funded by One Health Central and East Africa, Kampala, Uganda with a Contract Number 0714/07/District Health Systems-07.

\section{Publisher's Note}

Springer Nature remains neutral with regard to jurisdictional claims in published maps and institutional affiliations.

Received: 15 May 2018 Accepted: 6 July 2018

Published online: 13 July 2018

\section{References}

1. World Health Organization. The World Health Organization Report health systems financing: the path to Universal Coverage. Geneva: World Health Organization; 2010

2. World Health organization. State of health financing in the african region. Geneva: World Health organization; 2013.

3. United Nations, African Union U. MDG report 2013, food security in Africa: issues, challenges and lessons. Lagos: United Nations, African Union U; 2013.

4. Ministry Of Health (Federal Democratic Republic of Ethiopia). Health sector transformation plan.

5. Ministry Of Health (Federal Democratic Republic of Ethiopia). Health sector strategic plan (HSDP-III). Addis Ababa: Ministry Of Health; 2009.

6. Ministry Of Health (Federal Democratic Republic of Ethiopia). Health Sector Development Programme IV 2010/11-2014/15. 2014.

7. Ministry Of Health (Federal Democratic Republic of Ethiopia). Ethiopia's Fifth National Health Accounts. 2014.

8. Coelli T. A Guide to DEAP Version 2. 1 : a data envelopment analysis (Computer) Program. 1994:1-49.

9. Charnes A, Cooper WW, Seiford LM, Tone K. Data envelopment analysis: theory. Data envelopment analysis: a comprehensive text with models, applications, references and DEA-solver software. 2nd ed. Dordrecht: Academic Publishers; 1994. p. 1-490.

10. Ethiopian Standards Agency(ESA). Ethiopian standard Health CenterRequirements. 2012.

11. Kirigia JM, Sambo LG, Renner A, Alemu W, Seasa S, Bah Y. Technical efficiency of primary health units in Kailahun and Kenema districts of Sierra Leone. Int Arch Med. 2011;4(1):15. http://www.intarchmed.com/conte $n t / 4 / 1 / 15$.

12. Renner A, Kirigia JM, Zere E, Barry SP, Kirigia DG, Kamara C, et al. Technical efficiency of peripheral health units in Pujehun district of Sierra Leone: a DEA application. BMC Health Serv Res. 2005;5:77.

13. Akazili J, Adjuik M. Using data envelopment analysis to measure the extent of technical efficiency of public health centres in Ghana. Health Hum Rights. 2008. http://www.biomedcentral.com/1472-698X/8/11. Accessed 12 Dec 2014.

14. Marschall P, Flessa S. Efficiency of primary care in rural Burkina Faso. A two-stage DEA analysis. Health Econ Rev. 2011;1:1-15.

15. Kirigia JM, Emrouznejad A, Sambo LG, Munguti N, Liambila W. Using data envelopment analysis to measure the technical efficiency of public health centers in Kenya. J Med Syst. 2004:28(2):155-66.

16. Akazili J, Adjuik M, Chatio S, Kanyomse E, Hodgson A, Aikins M, et al. What are the technical and allocative efficiencies of Public Health Centres in Ghana? Ghana Med J. 2008:42:149-55. 